\title{
A high incidence of abdominal pregnancy in the Djungarian hamster (Phodopus sungorus)
}

\author{
P. Buckley* and A. Caine $\dagger$ \\ Medical Research Council, Radiobiology Unit, Harwell, \\ Didcot, Oxon. OX11 ORD, U.K.
}

\begin{abstract}
Summary. Eight animals with abdominal fetuses were found in a relatively small colony of Djungarian hamsters. All the fetuses were macerated. Some had remains of an amniotic sac with an umbilical attachment to a placenta adherent to the peritoneum, but others were without placental remains. Gross and histological examinations failed to reveal any ruptures of the uterus or oviducts. It was not possible to decide whether the abdominal pregnancies were primary or secondary.
\end{abstract}

\section{Introduction}

Although abdominal pregnancy has been recognised for over 900 years (Albucassis quoted by Masani, 1949), the condition is uncommon and still causes controversy as to whether it is primary, or secondary to rupture of the uterus or oviduct. A single case of primary abdominal pregnancy in man has been described by Maxwell, Eastman \& Smetana (1927), and BlandSutton (1904) and Schumann (1931) have described examples in the rabbit, dog, cat and man. A literature search has not revealed any record of the condition in other laboratory animals. The occurrence of 8 instances of ectopic pregnancy in a relatively small colony of Djungarian hamsters, within a period of 12 months, was therefore considered to be of interest. An attempt was made to determine whether the extra-uterine gestations were primary, or secondary to uterine rupture.

\section{Materials and Methods}

Three male and three female Djungarian hamsters (Phodopus sungorus) were obtained in November 1974 from the Institute of Cancer Research, Geneva, Switzerland. From these three breeding pairs a colony has been established at Harwell using a system of random outbreeding. Single males and females were put together at 8 and 12 weeks of age respectively and produced litters at intervals of 18 days or more. Young were weaned at 16-18 days of age. Approximately 90 breeding pairs have been used to maintain the stock and to provide animals for experiments.

Additional breeding pairs (89) were maintained during a reproductive capacity experiment following treatment of the females with $400 \mathrm{rad} \mathrm{X}$-rays, $1.6 \mathrm{mg}$ triethylenemelamine $/ \mathrm{kg}$ or 75 $\mathrm{mg}$ isopropylmethane sulphonate $/ \mathrm{kg}$ body weight. Irradiation was given bilaterally to the caudal two-thirds of the body and the chemical mutagens were dissolved in Earle's balanced saline solution (EBSS) and administered as a single intraperitoneal injection of approximately $1 \mathrm{ml}$. Control females received approximately $1 \mathrm{ml}$ EBSS intraperitoneally.

Diet consisted of Dixon's FFG/M mouse nuts (E. Dixon and Sons Ltd, Ware, Herts) supplemented with sunflower seeds and, for stock breeding pairs, a segment of orange twice weekly.

* Present address: Huntingdon Research Centre, Huntingdon, Cambridgeshire PE18 6ES, U.K. U.K.

† Present address: Department of Medical Genetics, Royal Hospital for Sick Children, Yorkhill, Glasgow G3 8SJ, 


\section{Results}

Out of a total of 179 females, 8 were found to have an abdominal pregnancy, giving an incidence of approximately $4.5 \%$ (Table 1). One animal (from stock) was found dead but the other 7 were killed because although they appeared pregnant they had failed to produce a litter at the expected time.

The variations in the length of the interval between the production of the last litter and the time that the hamster was killed (Table 1) were due to the system of management. Since this species was new to our laboratory all old breeding pairs were retained to observe for spontaneous pathology and to establish a normal lifespan. Consequently, these hamsters were only killed when they became moribund. The experiment to which the other females belonged was investigating the effects of chemical mutagens and radiation on fertility. It was decided that 3 months without a litter was a good indication of sterility, so at this time all females which had not produced a litter were examined. If fetuses were palpable in the abdomen then the animals were allowed to live longer. However, if parturition still did not occur the animal was killed. Thus it was often several months before the abdominal pregnancies were discovered.

Table 1. Reproductive history of the Djungarian hamsters with abdominal pregnancies

\begin{tabular}{|c|c|c|c|c|c|c|c|}
\hline Hamster & $\begin{array}{l}\text { Mutagen } \\
\text { injected }\end{array}$ & $\begin{array}{l}\text { Age when } \\
\text { killed } \\
\text { (months) }\end{array}$ & $\begin{array}{l}\text { Days from } \\
\text { last litter } \\
\text { to death }\end{array}$ & $\begin{array}{c}\text { No. of } \\
\text { previous } \\
\text { litters }\end{array}$ & $\begin{array}{l}\text { No. of } \\
\text { previous } \\
\text { offspring }\end{array}$ & $\begin{array}{l}\text { No. of } \\
\text { abdominal } \\
\text { fetuses }\end{array}$ & Observations \\
\hline A & None (stock) & 13 (died) & 110 & 3 & 6 & 3 & No placenta \\
\hline B & TEM & 10 & 142 & 4 & 16 & 5 & No placenta \\
\hline $\mathrm{C}$ & None (stock) & 10 & 107 & 4 & 9 & 1 & No placenta \\
\hline $\mathrm{D}$ & None (stock) & 14 & 38 & 10 & 25 & 3 & Peritonitis \\
\hline E & None (control) & 16 & 95 & 11 & 38 & 4 & $\begin{array}{l}1 \text { fetus with } \\
\text { placenta }\end{array}$ \\
\hline $\mathbf{F}$ & None (control) & 17 & 137 & 13 & 61 & 1 & Peritonitis \\
\hline G & IPMS & 14 & 43 & 13 & 41 & 2 & Peritonitis \\
\hline $\mathrm{H}$ & None (stock) & 16 & 36 & 20 & 99 & 5 & $\begin{array}{l}4 \text { fetuses with } \\
\text { placenta }\end{array}$ \\
\hline
\end{tabular}

TEM $=$ triethylenemelamine; IPMS $=$ isopropylmethane sulphonate

All the affected hamsters had previously produced normal litters in numbers ranging from 3 to 20 and with a total number of offspring from 6 to 99 (Table 1).

The number of ectopic fetuses varied from 1 to 5 and all were macerated, having the characteristic appearance of a fetus which had died and undergone degeneration in the absence of bacteria. Some were closely enveloped by the remains of an amniotic sac but others had no membranous coverings. In Hamster $\mathrm{H} 4$ out of 5 fetuses had umbilical attachments to placentae which were adherent to the abdominal wall (Plate 1). One of the 4 ectopic fetuses of Hamster E had a placenta attached to the abdominal surface of the diaphragm. All the other fetuses were lying free in the abdomen with no associated placentae (Table 1). All the fetuses had reached about the same stage of development at the time of their death and were advanced in gestation with good skeletal development and well differentiated limbs. The mean interval between the natural delivery of a living litter and death was 120 days for Hamsters $\mathrm{A}, \mathrm{B}$ and $\mathrm{C}$ with no placental remains, 95 days for Hamster $E$ with placental remains for 1 of 4 fetuses and 36 days for Hamster $\mathbf{H}$ with 4 of the 5 fetuses with placental attachments (Table 1).

The reproductive tract was normal in 7 females but Hamster $H$ had large cysts in both ovaries and a blood-filled cystic dilatation of the left horn of the uterus (Plate 1). No evidence of a recent or previous rupture of the uterus or oviducts was found in any of the affected hamsters. Three females had an associated purulent peritonitis with the ectopic fetuses embedded in the 
PLATE 1

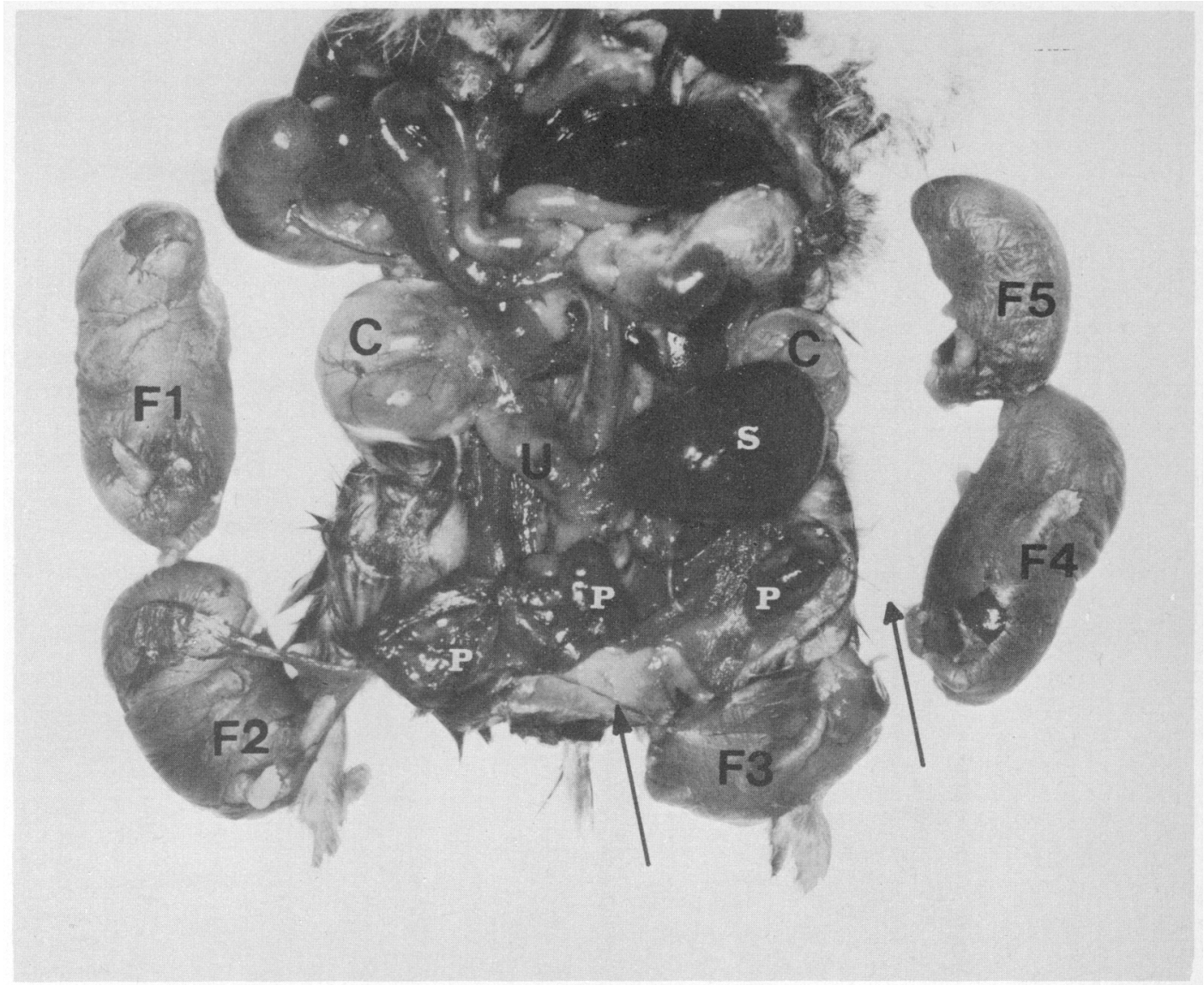

The abdomen of Hamster $\mathrm{H}$ showing the 5 extrauterine fetuses ( $\mathrm{F} 1-\mathrm{F} 5)$. The arrows point to the umbilical attachments of the placentae $(\mathrm{P})$ which are adherent to the peritoneum. Both ovaries have large cysts (C). The right horn of the uterus is labelled $U$ and the left horn, which has a blood-filled dilatation, $\mathrm{S}$.

(Facing p.680) 
exudates (Table 1). Samples were not taken for bacteriological examination, but no organisms were seen in the histological sections using Gram and Giemsa staining. Histological examination of the fetuses revealed only massive necrosis and differentiation of the tissues was difficult. The enveloping membranes, when present, were intensely eosinophilic and infiltrated with neutrophil leucocytes. Histological sections of the attachments of the placenta to the abdominal wall and diaphragm showed no evidence of true placentation, only the presence of a fibrinous peritonitis.

\section{Discussion}

Abdominal pregnancy may be divided into primary and secondary types. Primary abdominal pregnancy involves the extrusion of the ovum from the fimbriated end of the uterine tube into the peritoneal cavity, either after or possibly before fertilization, followed by implantation and development within the abdominal cavity. Secondary abdominal pregnancy follows rupture of the uterus or oviducts releasing the fertilized ovum or the developing embryo into the abdominal cavity. The placentae and membranes may or may not be expelled from the uterus into the abdominal cavity with the fetus.

Some reports describe allegedly primary cases (Maxwell et al., 1927; Masani, 1949), but the vast majority deal with secondary abdominal pregnancy (Bland-Sutton, 1904; Schlottauer \& Wakin, 1955; Fry \& Jones, 1973; McClure \& Chang, 1975). The authors cited agree that unless there is a placental attachment to the peritoneum the abdominal pregnancy should not be regarded as primary. Positive evidence of a uterine or tubal rupture is not considered essential to substantiate the diagnosis of the secondary type.

In women, approximately $1.3 \%$ of pregnancies are ectopic (Wilson, Beecham \& Carrington, 1971). The majority are tubal of which many will abort but some will progress to rupture the oviduct and give rise to a secondary abdominal pregnancy. However, the literature indicates that abdominal pregnancy is extremely uncommon in other animals. Lapin \& Yakovleva (1960) report only 3 abdominal pregnancies in 1892 pregnancies in monkeys $(0 \cdot 15 \%)$ and Schlottauer \& Wakin (1955) saw only one case (in the dog) during 30 years at the Mayo Institute of Experimental Medicine. No reports of abdominal pregnancies have been found in the limited literature on Djungarian hamsters. However, in our colony of Djungarian hamsters the incidence of abdominal pregnancy has reached approximately $0.4 \%$ of all pregnancies and approximately $4.5 \%$ of breeding females have been affected. There was no greater incidence in the females which had received mutagens.

The variation in the extent of the placentation associated with the abdominal fetuses was related to the number of previous litters and consequently also to the number of previous offspring; the higher the number of previous litters and offspring, the more likelihood there was of finding a placenta attached to the ectopic fetuses. In the three females with peritonitis no placentae were identified, but this may have been because of the extensive adhesions or destruction by an active inflammatory process. No hypothesis has been found to explain this correlation between placentation and the number of previous litters. However, the absence of placentae in 3 animals and of one placenta in Hamster $\mathrm{H}$ (Table 1), which had 5 ectopic fetuses but only 4 placentae, suggests that these cases of abdominal pregnancy were more likely to be secondary, the placentae having been extruded from the uterus along with the fetuses in some animals but not in others.

It seems unlikely that uterine rupture, an accidental phenomenon, would take place at the same stage of gestation in all animals unless this happened during parturition. With secondary abdominal pregnancy, therefore, the fetuses in the different litters would be expected to be of different sizes. If the rupture occurs only at parturition then the fetuses would be of similar size, but infection and peritonitis would probably follow since the cervix is open at parturition. Although peritonitis was present in 3 hamsters in the present series, no evidence of uterine rupture was found, although examination was difficult because of extensive adhesions, and no 
organisms were detected histologically, suggesting a sterile inflammatory response to the dead fetuses rather than an infective peritonitis.

On the other hand, primary abdominal pregnancy would be expected to result in dead fetuses of similar size given that death would occur at the stage when the crude placental attachment no longer provided sufficient nutrition. That abdominal fetuses can develop to an advanced stage without an elaborate placentation has been shown by the reports of pregnancy following ovariohysterectomy (Adams \& Schreier, 1957; Hanes, 1964; Carrig, Gourley \& Philbrick, 1972), presumably due to fertilized ova being extruded from the oviduct during surgery and developing in the abdomen.

In this series of hamsters there was no evidence, either gross or microscopic, of rupture of the uterus or oviduct, and all of the abdominal fetuses were of similar size and stage of development. Furthermore, the ectopic fetuses in 2 females had placentae which were adherent to the peritoneum. These findings suggest that the abdominal pregnancies might be primary whereas the facts presented above point to them being of a secondary nature. It is not possible with the evidence available to state categorically whether these abdominal pregnancies were primary or secondary.

In our Djungarian hamsters the interval between normal births ranges from 18 to 25 days. This degree of variation may be due to a degree of infertility in the post-parturient matings or possibly to delayed implantation. If delayed implantation proves to be the cause this could be a factor in this high incidence of abdominal pregnancy, whether it is primary or secondary, since an unimplanted fertilized ovum may be expelled from the uterus into the oviduct or even into the abdominal cavity. However, no reports of abdominal pregnancy have been found in the literature on those species which are known to exhibit delayed implantation.

We thank Dr E. V. Hulse, Dr M. F. Lyon and Dr R. H. Mole for helpful advice and encouragement of this investigation; also all the technicians who cared for the hamsters during this study and Mrs A. B. Bates for preparation of the manuscript.

\section{References}

Adams, J.Q. \& Schreier, P.C. (1957) Abdominal pregnancy subsequent to total hysterectomy. $A m . J$. Obstet. Gynec. 73, 680-682.

Bland-Sutton, J. (1904) Abdominal pregnancy in women, cats, dogs and rabbits. Lancet ii, 16251627.

Carrig, C.B., Gourley, I.M. \& Philbrick, A.L. (1972) Primary abdominal pregnancy in a cat subsequent to ovariohysterectomy. J. Am. vet. med. Ass. 160, 308310.

Fry, P.D. \& Jones, S.C. (1973) A case of ectopic pregnancy in a cat. $J$. small Anim. Pract. 14, 361365.

Hanes, M.V. (1964) Ectopic pregnancy following total hysterectomy. Report of a case. Obstet. Gynec. 23, 882-884.

Lapin, B.A. \& Yakovleva, L.A. (1960) Comparative Pathology in Monkeys, pp. 215-217. Charles C. Thomas, Illinois.
Masani, K.M. (1949) Ectopic Pregnancy. The Popular Book Depot, Bombay 7.

Maxwell, J.P., Eastman, N.J. \& Smetana, H. (1927) Primary abdominal pregnancy. Surgery, Gynec., Obstet. December, 802-804.

McClure, H.M. \& Chang, J. (1975) Ectopic pregnancy in a squirrel monkey. J. Am. vet. med. Ass. 167, 654 655 .

Schlottauer, C.F. \& Wakin, K.G. (1955) Ectopic pregnancy in a dog. J. Am. vet. med. Ass. 127, 213.

Schumann, E.A. (1931) Extra-uterine pregnancy. Gynecological and Obstetrical Monographs, Vol. VII. D. Appleton and Company, New York.

Wilson, J.R., Beecham, C.T. \& Carrington, E.R. (1971) Obstetrics and Gynecology, p. 180, 4th edn. C.V. Mosby Company, St. Louis, Missouri.

Received 29 December 1978 